Original Article

\title{
A COMPREHENSIVE STUDY OF STERNAL FORAMEN IN DRY STERNUM
}

\author{
Alok Tripathi, Ajay Kumar, Shobhit Raizaday, Satyam Khare, Shilpi Jain, \\ Ram Kumar Kaushik, Hina Kausar, Shweta \\ Department of Anatomy, Subharti Medical College, Meerut, UP, India
}

\begin{abstract}
Introduction: Congenital defects during the development of sternum give rise to sternal foramen. These defects are due to incomplete fusion of sternebrae. Serious life-threatening complications can occur during sternal puncture for bone marrow biopsy. Therefore, knowledge of the presence of sternal foramen is important to prevent these life-threatening complications. Our aim was to observe the incidence, location, number and shape of the sternal foramen in dry sterna.
\end{abstract}

Material \& Methods: The present study was conducted in Department of Anatomy, Subharti Medical College, Meerut in 100 dry sterna. Various types of sternal variations were observed and documented.

Results: In our study, $10 \%$ of the sterna had a sternal foramen. Single sternal foramen was present in 8 specimens (8\%). Double foramina were present in 2 bones $(2 \%)$.

Conclusion: Sternal foramen are not uncommon. Knowledge of these variations are important for radiologists and surgeons during bone marrow biopsy.

Keywords: Sternum, foramen, site, shape.

\section{INTRODUCTION}

The human sternum consists of cranial manubrium (prosternum), an intermediate body (mesosternum) and a caudal xiphoid process (metasternum) [1]. The sternum is formed by fusion of two cartilaginous sternal plates flanking the median plane. Arrangement and number of ossification centres vary in relation to completeness and the time of fusion of the sternal plates. Incomplete fusion leaves a sternal foramen [1]. Anatomical knowledge of variations of sternum are imperative as their awareness is important for bone marrow aspiration procedure. Defects of the sternum are commonly reported in the lower third as single midline foramen [2]. These sternal foramina are commonly asymptomatic and detected in routine CT scans [3]. The comprehensive study of the sternal foramen is important in acupuncture practices and sternal marrow aspiration to prevent the damage to vital structures like heart and pericardium. The aim of the present study was to find the incidence, site, shape and number of sternal foramen, if present.

\section{MATERIAL AND METHODS}

The present study was carried out on 100 dry sterna in the department of Anatomy, Subharti Medical College, Meerut. The morphometry of sternum and sternal variations were observed and documented. 


\section{OBSERVATIONS AND RESULTS}

In our study, the sternal foramen was present in 10 sterna out of 100 specimens (10\%). In the remaining bones, sternal foramen was absent $(90 \%)$. In eight sterna $(8 \%)$, the foramen was single and in two sterna $(2 \%)$, the foramen was double (Fig. $1 \& 2)$.

Out of 10 sterna having sternal foramen, the foramen was present over the manubrium in 2 bones $(2 \%)$, over the body in 4 bones $(4 \%)$, over the xiphoid process in 3 bones (3\%) and at the xiphisternal articulation in one bone (1\%). Double foramen was present in two sterna over manubrium (Fig. 1-3).

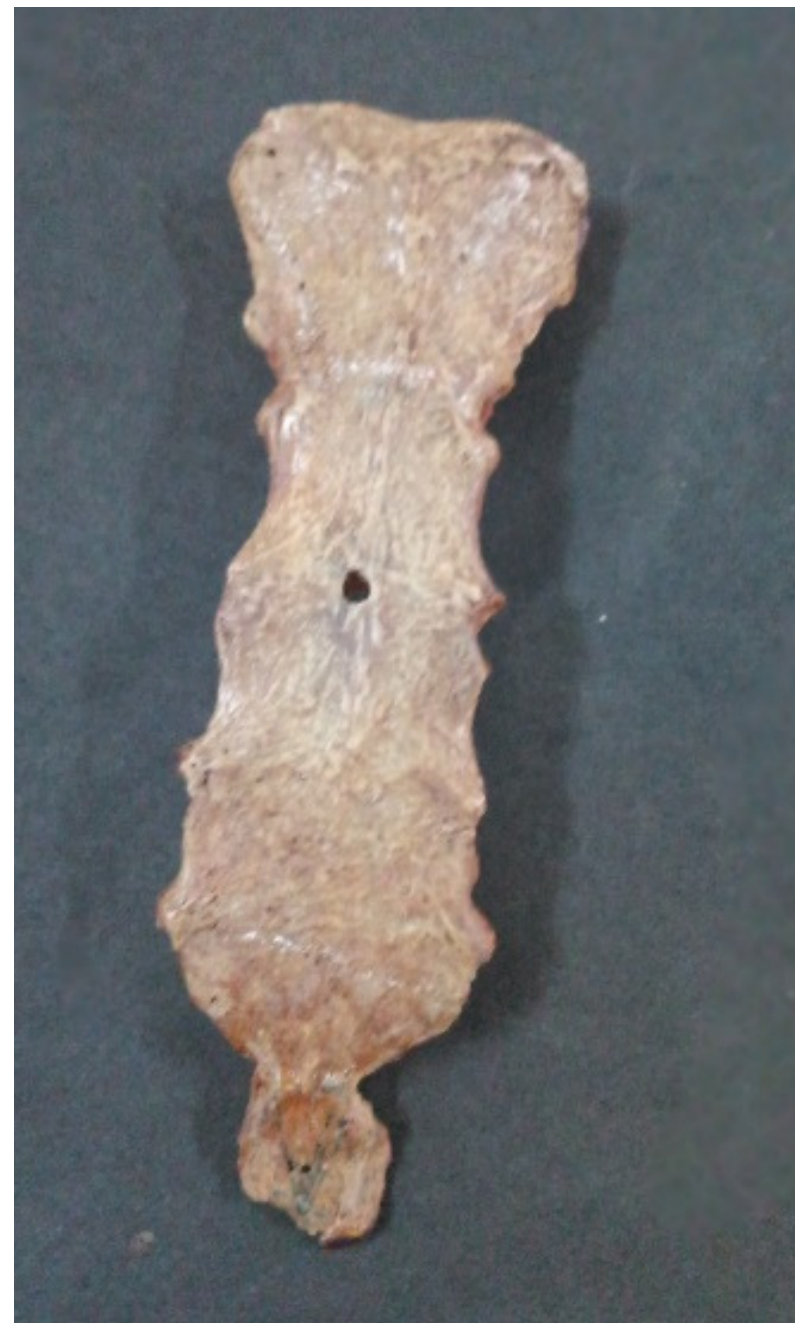

Fig. 1. Single sternal foramen over the body

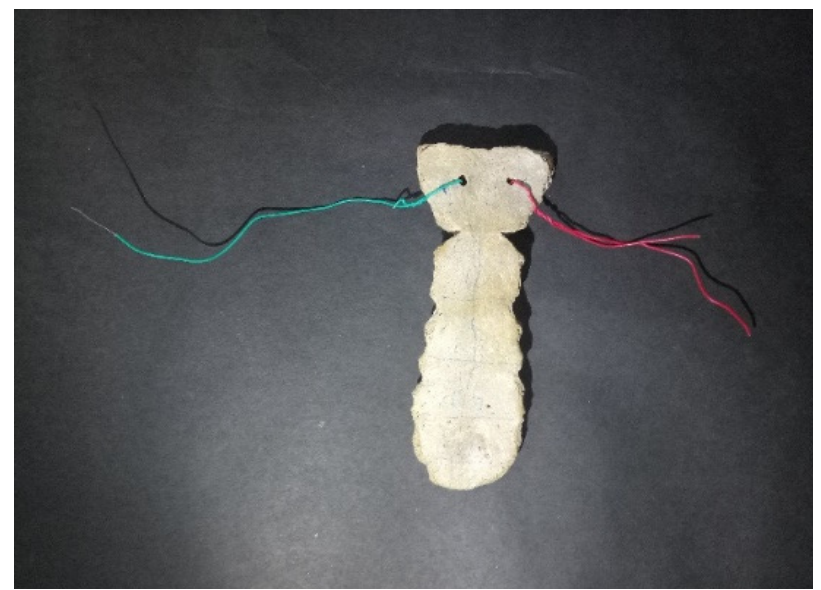

Fig. 2. Double sternal foramen over manubrium

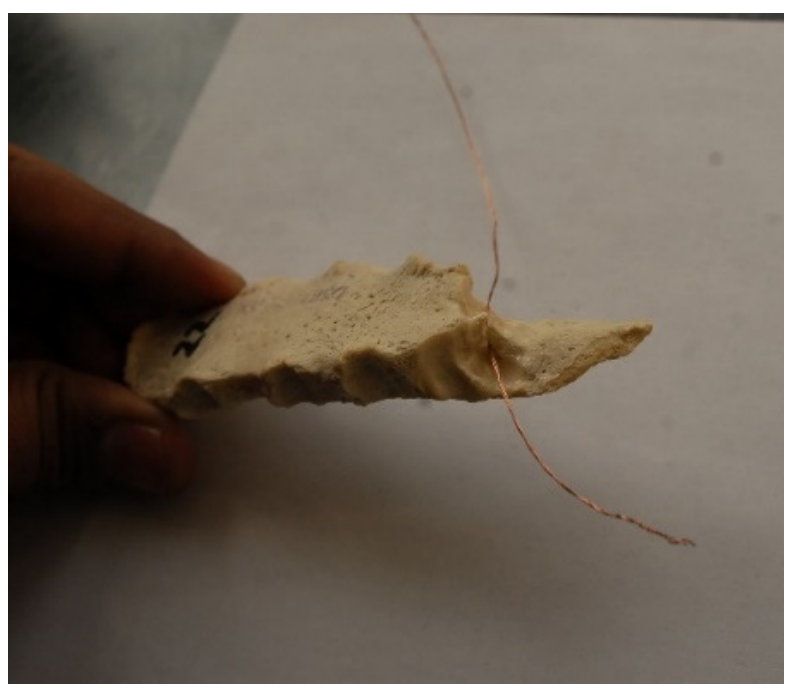

Fig. 3. Single sternal foramen over xiphisternal articulation

Shape of the foramen over manubrium and body was round $(6 \%)$ while those over the xiphoid process and xiphisternal articulation were oval (4\%).

\section{DISCUSSION}

\section{Incidence of sternal foramina}

In our study, the percentage of the presence of sternal foramen was $10 \%$. It was more than that reported by Cooper et al. (6.7\%) [4] while less than that documented by other studies [5-8] (Table 1). 
Study of sternal foramen......

\section{Site of sternal foramina}

Site of sternal foramen was reported to be maximum in the body of sternum $[5,6,9]$. In our study, the incidence of sternal foramen over the body of sternum was $4 \%$ which was maximum than noted at other sites (Table 1) and this finding runs parallel with the above mentioned studies. The presence of sternal foramen over the manubrium was $2 \%$ in our study which is similar to that reported by Arumugam \& Hemalatha (2018) [8]. In 3\% cases, the sternal foramen was present on xiphoid which is different from that noted by some previous studies $[8,10]$.

Table 1: Site and incidence of sternal foramen in various studies

\begin{tabular}{|l|c|c|c|c|c|c|}
\hline Authors & Year & Manubrium & Body of sternum & Xiphoid & $\begin{array}{c}\text { Sterno- } \\
\text { xiphoid }\end{array}$ & $\begin{array}{c}\text { Incidence of } \\
\text { sternal } \\
\text { foramen }\end{array}$ \\
\hline Cooper et al. [4] & 1988 & Not specified & 1 specimen & - & - & $6.7 \%$ \\
\hline Jakhar et al. [11] & 2015 & - & $\begin{array}{c}1 \text { specimen over } \\
\text { lower third }\end{array}$ & - & - & 1 specimen \\
\hline $\begin{array}{l}\text { Kumarasamy \& Agarwal } \\
\text { [12] }\end{array}$ & 2011 & - & 1 specimen & - & - & 1 specimen \\
\hline Busaid et al [6] & 2011 & - & $81.8 \%$ & - & - & $13.8 \%$ \\
\hline Tandon \& Gara [13] & 2016 & - & 1 specimen & - & - & \\
\hline $\begin{array}{l}\text { Gkantsinikoudis et al. } \\
\text { [9] }\end{array}$ & 2017 & - & $40 \%$ & $40 \%$ & - & $14.2 \%$ (male), \\
\hline \begin{tabular}{l} 
Babinski et al. [5] \\
\hline
\end{tabular} & 2015 & - & $\begin{array}{c}38.5(5 \text { th } \\
\text { segment), } 64.2 \\
\left(4^{\text {th }}-5^{\text {th }} \text { segment) }\right.\end{array}$ & - & - & $16.6 \%$ \\
\hline $\begin{array}{l}\text { Arumugam \& } \\
\text { Hemalatha [8] }\end{array}$ & 2018 & $2 \%$ & $6 \%$ & $6 \%$ & - & $14 \%$ \\
\hline Present study & 2019 & $2 \%$ & $4 \%$ & $3 \%$ & $1 \%$ & $10 \%$ \\
\hline
\end{tabular}

\section{Number and shape of sternal foramina}

Balta (2018) [14] in radiological study documented the incidence of double sternal foramina in body of sternum. Arumugam \& Hemalatha (2018) [8] also stated double sternal foramina over the manubrium in one bone and in other specimens, double sternal foramina in xiphoid process. In our study, two double sternal foramina were present and both were present over the manubrium. Cooper et al. (1988) [4] reported double sternal foramina located in body of sternum and over manubrium also. Vora et al (2014) [15] and Yekeler et al. (2006) [16] reported one single sternal foramen. In our study, both single and double sternal foramen were present. Selthofer et al. (2006) [10] reported oval type of sternal foramen. In or study, both oval and round type of sternal foramen were present.

\section{CONCLUSION}

Life-threatening complications like cardiac tamponade and pneumothorax should be kept in mind before performing bone marrow biopsy, acupuncture etc. due to the presence of sternal foramen. So, it is advisable to take $x$-ray to rule out such variations of the sternum.

\section{REFERENCES}

1. Standring S. The anatomical basis of clinical practice. Gray's Anatomy, $37^{\text {th }}$ ed. $3^{\text {rd }}$ Chapter 1989.

2. Bermio VS, Jos Hemlatha GA. Congenital foramen in the body of sternum. Int J Anat Res. 2014; 2(3): 545-48.

3. Fokin AA. Cleft sternum and sternal foramen. Chest Surg Clin N Am. 2000; 10 (2):261-76. 
4. Cooper PD, Stewart JH, McCormick WF. Development and morphology of the sternal foramen. American J Foren Med Pathol. 1988; 9 (4):342-7.

5. Babinski MA, de Lemos L, Babinski MS, Gonçalves MV, De Paula RC, Fernandes RM. Frequency of sternal foramen evaluated by MDCT: a minor variation of great relevance. Surg Radiol Anat. 2015; 37 (3): 287-291.

6. Busaid HEL, Kaisha W, Hassanali $J$ et al. Sternal foramina and variant of xiphoid morphology in Kenyan population. Folia Morphol. 2011; 71 (1): 19-22.

7. Kirum GG, Munabi IG, Kukiriza J, Tumusiime G, Kange M, Ibingira $\mathrm{C}$, Buwembo $\mathrm{W}$. Anatomical variations of the sternal angle and anomalies of adult human sterna from the Galloway osteological collection at Makerere University Anatomy Department. Folia Morphol. 2017; 76 (4): 689-94.

8. Arumugam K., Hemalatha GAJ. Morphometric study of sternal foramen in adult human dry sternum. Int J Anat Var. 2018; 11(4): 111-14.

9. Gkantsinikoudis N, Chaniotakis C, Gkasdaris G, Georgiou N, Kapetanakis S. Morphological approach of the sternal foramen: an anatomic study and a short review of the literature. Folia Morphol (Warsz). 2017; 76 (3):484-90.
10. Selthofer R, Nikoli $\square$ V, Mrcela T, Radi $\square$ R, Leksan I, Rudez I, Selthofer K. Morphometric analysis of the sternum. Coll Anthropol 2006; 30 (1): 43-7.

11. Jakhar JK, Dagar T, Dhattarwal SK, Pal V. The sternal foramen: the possible forensic misinterpretation of an anatomic abnormality. J Indian Acad Forensic Med. 2015; 37 (3):315 316.

12. Kumarasamy SA, Agarwal R. A large sternal foramen. Int J Anat Var. 2011; 4:195-6.

13. Tandon A, Gara RD. Sternal foramen case report. Med J DY Patil Univ. 2016; 9 (1):127-8.

14. Balta C. An anatomic abnormality: double sternal foramina. Int $\mathrm{J}$ Clin Med Imaging. 2018; 5 (3).

15. Vora DH, Shah JP, Mangal HM et al. Post mortem study of congenital anomalies of sternum bone. NJIRM. 2014; 5:37-9.

16. Yekeler E, Tunaci M, Tunaci A, Dursun M, Acunas G. Frequency of sternal variations and anomalies evaluated by MDCT. AJR Am J Roentgenol. 2006; 186(4): 956-60. 